\title{
Antecedents and Consequences of Idiosyncratic Deals: A Frame of Resource Exchange
}

(C) Higher Education Press and Springer-Verlag 2011

\begin{abstract}
This study examines the antecedents and consequences of both timing and content of idiosyncratic deals (i-deals) for attracting and retaining valuable employees. A resource exchange frame theorizes the influence pattern of personal individualism value, social skill, and perceived insider status on i-deals timing. Individualism and social skill are expected to relate to both $e x$ ante and ex post i-deals; perceived insider status is anticipated to relate only to ex post i-deals. The frame also suggests that i-deals' content and personal development relate primarily to relational and balanced psychological contracts; the other ex post i-deals, flexibility and workload reduction relate to transactional psychological contracts. The frame was tested with data collected from 289 Chinese employees in the telecommunication industry.
\end{abstract}

Keywords idiosyncratic deals, resource exchange, individualism, social skill, perceived insider status

\section{Introduction}

In today's business environment, human resources have increasingly become a source of competitive advantage. For example, interpretation of business

Received July 14, 2010

Cynthia Lee $(\square)$

Department of Management \& Marketing, Hong Kong Polytechnic University, Hong Kong, China

College of Business Administration, Northeastern University, Boston, MA 02115, USA

E-mail: msclee@polyu.edu.hk; c.lee@neu.edu

Chun Hui

School of Business, University of Hong Kong, Hong Kong, China

E-mail: chui@business.hku.hk 
opportunities and resolution of environmental challenges can hardly be accomplished through machines. Instead, they take judgment and wisdom of employees. Idiosyncratic deals are tools for attracting and retaining value-added employees (Rousseau, 2001a). Defined by Rousseau, Ho, and Greenberg (2006), idiosyncratic deals refer to the special conditions that individual workers bargain for, and that differ from the standards applying to their peers (e.g., customized duties, individualized career opportunities, flexible work hours, and variability in workload, etc). Hornung, Rousseau, and Glaser (2008), using a German sample, found that personal initiative and work arrangements promoting the individualization of employment conditions were positively related to the negotiation of i-deals. They also found two i-deals contents, flexibility in work hours and development opportunities, have differential effects on work-family conflict, unpaid overtime work, performance expectations and affective commitment. The study by Hornung et al. (2008) indicated important directions for studying i-deals. First, it might be fruitful to examine individual antecedents to i-deal. Second, the content and other characteristics of i-deals may play a role in both what employees seek to individualize in their jobs, as well as the outcome of such individualization.

Our objective is to examine antecedents and consequences of i-deals using the exchange of resources theoretical framework in a competitive industrytelecommunication. First, based on the resource theory, we identify three different personal resource antecedents to i-deals. Second, we examine how these antecedents relate to the seeking of different types of i-deals in terms of the timing, that is, ex ante i-deals (negotiated prior to employment) and ex post i-deals (negotiated after employment). Third, we examine the relationship between the negotiation of i-deals and employee psychological contracts. Psychological contracts are the specific manner in which the employee and employer in the exchange relationship interpret their obligations with each other (Rousseau, 1995). Lastly, we examine the generalizability of i-deals theory to China.

\section{Theoretical Framework and Hypotheses}

We examine the antecedents and consequences of i-deals using the resource exchange framework. In the competitive global environment, in order to attract and retain value-added human resources, employers are willing to negotiate and grant i-deals (Rousseau, 2001a). In the resource-based view of the firm in the strategy literature, the organization owns both tangible and intangible resources. Wernerfelt (1984) defines resources as "those assets (including tangible and intangible) which are tied semi-permanently to the firm" (p. 172). Because many resources, such as human resources, are firm-specific and not perfectly mobile or imitable, firms are continuously heterogeneous in terms of their resource base. 
Having a strong resource base can increase the firm's competitive advantage.

In the organizational behavior literature, Foa and Foa (1976) define resources as anything that can be transmitted from one person to another. According to Foa and Foa's $(1974 ; 1980)$ exchange wheel theory, there are six empirically distinguishable categories of resources in exchange. These resources are, in order from low to high level of particularism (the extent to which the value of a given resource is influenced by the particular persons involved in the exchange): money, information, services, goods, status, and love. As argued by Rousseau and Kim (2006), all employment arrangements involve the exchange of resources between the two parties (employer and employee). The individuals bring with them their personal resources in terms of time, effort, and competence to work in exchange for economic and social resources. Economic resources are usually discrete and well-specified involving monetary arrangements (such as pay, benefits, vacation, and personal days) in exchange for specific services and performance levels contributed by the employee. Social resources, on the other hand, are non-monetary and particularistic. They can derive from high-quality employee-supervisor (or employer) relations that are social and relational in nature where the employee and employer provide mutual support and responsiveness to each other's needs (Rousseau, 1995; Rousseau and Kim, 2006). Both economic and social resources contribute to why i-deals are negotiated, specify i-deals' relationship to psychological contracts and the consequences that benefit both the employee and the employer.

\subsection{Timing of i-Deals}

i-deals can be negotiated by employees either prior to employment or after they are on their jobs (Rousseau, Ho, and Greenberg, 2006). Those negotiated prior to employment are called ex ante i-deals and those negotiated after employment are ex post i-deals. Rousseau (2005) suggests that ex ante i-deals are more likely where an employee has a high degree of market power. However, ex post i-deals are more likely after the employee has been on the job since the job experience provides the employee the opportunity to build a performance record and a relationship with his/her employer. Rousseau, Ho, and Greenberg (2006) suggest that people are more likely to negotiate ex post $\mathrm{i}$-deals than ex ante i-deals. This is because ex ante i-deals may be limited in settings where labor law practices are highly regulated and cultural norms constrained people's negotiation behavior. Rousseau (2005) further suggests that ex ante i-deals negotiation is considered rude in more collectivistic cultures such as Japan or Singapore. Ex post i-deals, on the other hand, occur after the employee have started work when both the employer and the employee have time to learn about each other's interests, resources and capabilities. 


\subsection{Individualism and Timing of i-Deals Negotiation}

Personal values have been conceptualized as desirable, trans-situational goals, varying in importance, that serve as guiding principles in people's lives (e.g., Rokeach, 1973; Schwartz, 1992). Values help guide the selection and evaluation of actions, events, and people (Peterson, Ranganathan, Chi, Tsai, and Chan, 2006). Therefore, a person's individual values will influence the way that person perceives his/her value and personal resources he/she brings to the organization and whether the employee will engage in i-deals negotiation. For example, Hornung et al. (2008) suggest that those with proactive personality should devise, ask for, and negotiate arrangements benefiting themselves and their employers. They found that personal initiative was positively related to two types of ex post i-deals: flexibility work arrangement and developmental i-deals.

We propose that the core values of individualism, or a concern for oneself and immediate family, an emphasis on personal autonomy and self-fulfillment, and the basing of one's identity on one's personal accomplishment (Hofstede, 1980), should relate to the negotiation of i-deals. This is because those with individualistic values tend to focus on personal responsibility and freedom of choice (Waterman, 1984), prefer individually-based compensation and equity allocations (Earley and Gibson, 1998). Chen (1995), for example, points out that individualistic Chinese are economically oriented and prefer to invoke differential rules or unequal distribution of material and socio-emotional rewards. On the other hand, collectivistic employees, even they could, tend not to ask for special treatment in order to maintain harmonious work relationships. It is likely that those with individualistic values will engage in i-deals negotiation that maximizes the resources they can obtain from their employers. Since internal values' influence on personal behavior is trans-situational, stable, and enduring (Rohan, 2000), we predict that individualistic employees' negotiation of i-deals will occur before and after organizational entry. Thus, we predict that:

H1 Individualism relates positively to ex ante and ex post i-deals.

\subsection{Social Skill and Timing of i-Deals Negotiation}

"Social skill reflects interpersonal perceptiveness and the capacity to adjust one's behavior to different situational demands and to effectively influence and control the responses of others" (Ferris, Witt, and Hockwarter, 2001). According to Ferris et al. (2001), individuals high in social skills can more accurately interpret social cues, read between the lines, and can identify other's true intention. As well, people with social skills are better able to determine the appropriate timing to exercise an influence attempt. Research by Hochwarter, Witt, Treadway, and 
Ferris (2006) demonstrate the relevance of social skill on job performance may be dependent on contextual cues. Further, Witt and Ferris (2003) in four studies show that social skill moderates the conscientiousness-performance relationship.

We propose that social skill, reflecting on the degree of mastery already acquired, is a form of personal resource that helps individuals negotiate i-deals. The socially skilled individuals are more likely than those low in the skill to effectively bargain for specific employment arrangements prior to and after organizational entry. We, therefore, predict that:

H2 Social skill relates positively to ex ante and ex post i-deals.

\subsection{Perceived Insider Status and Timing of i-Deals Negotiation}

While individualism and social skills reflect employee's personal resources enabling them to bargain for themselves, "the extent to which an individual employee perceives him or herself as an insider within a particular organization" (Stamper and Masterson, 2002), or perceived insider status relates to the employee's social resources. We examine employee's perceived insider status (PIS), a form of social exchange that occurs between the employee and the organization, in relating to the negotiation of ex post ideals. Blau's (1964) social exchange theory suggests that the dyadic relationships and work roles developed over time between the leader and the follower are from a series of exchanges. Through the series of exchange relationships, the workers who become members of the highly trusted in-group have greater latitude over duties and responsibilities. Those who become members of the out-group often are denied of any special treatment that the in-group members enjoy. Just like the relationship with the supervisor takes time to build, it takes time to develop feelings of being an "insider" of the organization.

From the employer side, he/she may have learned the values of this specific employee and that granting i-deals is a form of reward for the employee's contribution. The employer may be reluctant to negotiate any i-deals early in a relationship with the employee. From the employee side, given the passage of time, he/she may have developed a person-specific feelings for the organization from whose personal base of power they can negotiate valued resources and opportunities. Those employees who prefer something non-standard would seek i-deals only if they perceive the likelihood of a successful negotiation. Among many reasons employees seek i-deals from their employers, ex post i-deals are more likely to be negotiated when employees perceived they have insider status in the organization. Thus, personal relationship between the employee and the employer plays a critical role in ex post i-deals. We, therefore, predict that:

H3 Perceived insider status relates positively to ex post i-deals. 


\subsection{Timing of i-Deals and Contracting}

Ex ante and ex post negotiated i-deals are likely to differ in their implications for employment relationship (Rousseau, Hornung, and Kim, 2008). Psychological contract, initiated by Argyris (1960) and refined and by Rousseau (1995), reflects the reciprocation of inner obligations of both parties involve in the employment relationship, the employee and the employer. One party's increase or demission of obligations normally indicates corresponding fluctuation of the other party's obligations. Psychological contract has been theorized on a highly generalizable social exchange framework, which distinguishes three typical employment relationships basing on economic or social exchange (Blau, 1964). Economic exchange is marked by short-term interactions involving specific, limited exchange of resources as in the transactional contract. Social exchange is marked by more open-ended relationships both in terms of time frame and broader array of resources exchanged as in the relational and balanced contracts (Rousseau, 1995).

Without any organizational experience at the time of ex ante negotiation, potential employees typically bargain for economic resources reflecting material and monetary resources (Rousseau et al., 2008). Consistent with the social exchange theory and the norm of reciprocity (Blau, 1964), employees are more likely to reciprocate by engaging in transactional obligations when the granted i-deals reflect economic resources. However, the ex post i-deals will be based more on non-monetary or social resources. The employee who successfully negotiated the ex post i-deals is likely to interpret the i-deals as an indication of the employer's valuing the employee's contribution and recognizing the employee's needs (Rousseau, Ho, and Greenberg, 2006). Thus, the employee will more likely reciprocate employers' provision of social resources by engaging less in transactional psychological contract but by engaging more in relational and balanced forms of psychological contracts. Relational psychological contract refers to a long-term arrangement without specific performance-reward contingencies (Rousseau, 1995). A relational contract, in essence, involves a mutually satisfying relationship with open-ended arrangements that include socio-emotional as well as economic terms. The third form, balanced psychological contract, combines an open-ended relational emphasis with the transactional feature of well-specified performance-reward contingencies (Rousseau, 1995). These two forms of psychological contracts reflect the quality of the employer-employee that is social in nature and indicates the future opportunities of the employee in the organization. We therefore predict that:

H4 Ex ante i-deals relate more positively to transactional psychological 
contract than ex post i-deals.

H5 Ex post i-deals relate more positively to relational and balanced psychological contracts than ex ante i-deals.

\subsection{Ex post i-Deals' Content and Contracting}

According to Hournung et al. (2008), content of i-deals involves a wide array of resources, from tangible and universalistic (e.g., payment, material goods, work hours) to abstract and particular (e.g., training, skill development). Rousseau (2005) and Rousseau and Kim (2006) identify three forms of ex post i-deals: professional development opportunities, flexible work hours, and workload reduction. Developmental i-deals refer to the special opportunities to use and expand one's competencies and pursue career advancement (Rousseau et al., 2008). This form of i-deals is more abstract and social in nature and primarily based on the quality of employment relationship reflecting the relational and balanced psychological contracts. Flexibility i-deals refer to the special work schedule while workload reduction i-deals refer to the special arrangement in reducing workload and work hours. The latter two forms of i-deals are economic in nature and are concrete and universal reflecting the transactional psychological contracts. We thus predict that:

H6 Personal development i-deals relate more positively to relational and balanced contracts while flexibility and workload reduction i-deals relate more positively to transactional contracts.

\section{Methods}

\subsection{Sample and Procedure}

As part of a larger study, data were collected from thirteen companies in the Chinese telecommunications sector in 2006. Sampling from multiple companies within the same industry ensured variation in employer psychological contract and avoided contextual constraints associated with any particular industry (Rousseau and Fried, 2000). Among the companies, 9 were subsidiaries of China Unicom which were located in south China, while the other 4 were subsidiaries of China Telecom which operated in north China.

To collect the data, we first approached both the CEO and (or) the HR manager in each company for approval. We then obtained a copy of the organizational chart from the HR manager, and a list of the names of middle managers and their direct subordinates. We constrained the hierarchical levels of our participants within organizations to control for differences in job levels, so that we targeted the direct subordinates of middle managers. We administrated 
two waves of data collection from the target subordinates. There was a six-week temporal separation between the two waves to reduce common method variance problems (Podsakoff, MacKenzie, Lee, and Podsakoff, 2003). Participants were first briefed by one member of the research team on the overall information of the project. They were then asked to complete the survey on company time. Questionnaires were collected thirty minutes after being distributed by the research team. In the first wave, employees provided information including social skill, perceived insider status, timing of i-deals negotiation and ex post i-deals content, and their demographics. In the second wave, they responded to questions on individualism, and employee and employer psychological contracts.

Across the thirteen companies, we distributed questionnaires to 360 employees in the fist wave and got $100 \%$ response rate because of the researcher's personal visit. A total of 289 employees from eleven companies responded to the second wave of our survey, resulting in a valid response rate of $80 \%$. Among the 289 employees, $48 \%$ were male, $95 \%$ held college degree or above. The average age was about 30 years (S.D. $=5.15$ ) with a minimum age of 21 and a maximum age of 52; the average organization tenure was 5.35 years $(S . D .=3.99)$ with a maximum of 25 years.

\subsection{Measures}

To assure measuring equivalence in the Chinese and English versions, all the scales used in this study were translated into Chinese and then translated independently back into English (Brislin, 1980). Expert judges in the Chinese language examined the questionnaire to ensure that the items were interpretable in Chinese. Unless noted, all multiple-item measures used a five-point Likert-type response scale ranging from "strongly disagree" (1) to "strongly agree" (5).

Individualism was measured using the 8 -item scale originally developed by Earley (1993). A sample item was "To be superior, a person must stand alone." The Cronbach's alpha of this scale was 0.71 .

Social skill was measured at Time 1 using the 7 -item scale developed by Ferris et al. (2001). A sample items was "I find it easy to put myself in the position of others." The Cronbach's alpha of this scale was 0.80 .

Perceived insider status was measured using the 6-item scale developed by Stamper and Masterson (2002). A sample item was "I feel very much a part of my work organization." The Cronbach's alpha of this scale was 0.84 .

Timing of i-deals: Ex ante i-deals and ex post i-deals were each measured by two items developed by Rousseau and Kim (2006). We asked the respondents to indicate on a 5-point scale, ranging from "a great extent" (5) to "not al all" (1), to describe the extent to which they have negotiated special arrangements. The $e x$ 
ante i-deals items were, "At the time I was hired, I negotiated for work arrangements that differ from the typical employee here (e.g., work hours and job duties)," and "At the time I was hired, I negotiated for particular employment conditions that suit me personally." The Cronbach's alpha of this scale was 0.81 . The ex post i-deals items were "After I worked here for a while, I have been able to negotiate special arrangements that suit me personally," and "After I worked here for a while, I have been able to negotiate with my supervisor to create arrangements that suit me personally." The Cronbach's alpha of this scale was 0.61 .

Content of i-deals was measured at Time 1 by adapting Rousseau and Kim's (2006) scales. Employees indicated the extent to which they had asked for and had successfully negotiated specific aspects of individual employment arrangements (on a yes/no response format). As in Rousseau and Kim (2006), these ex post i-deals reflect 3 content areas of:

(1) Personal development i-deals were based on 4 items: "Special opportunities for skill development," "Individualized performance goals," "Ways to make job more enjoyable," and "Career development."

(2) Flexibility i-deals were based on 2 items: "Flexibility in starting and ending my work day," and "Schedule different from coworkers."

(3) Reduced workload i-deals were based on 2 items: "Reduced work demands," and "Reduced work hours."

The Cronbach's alpha coefficients for these 3 scales were $0.82,0.64$, and 0.65 , respectively. The reliability coefficients for flexibility and reduced workload i-deals, though marginal, were still within the acceptable range for scales in the developmental stage (Nunnally, 1978). As in Hornung et al. (2008), we conducted confirmatory factor analyses (CFAs) with maximum likelihood estimation using LISREL 8.30 to assess our measures' factor structure and the extent of common method bias. Specifically, we compared the three-factor i-deals measurement model with two alternative models: an one-factor model in which all 8 items loaded to a "grand" i-deals factor, and an four-factor model that were obtained via adding an independent "common method factor" to the three-factor model. Results indicated the three-factor model provided a better fit to the data $\left(\chi^{2}=41.28\right.$, d.f. $=17$; TLI $=0.93$, IFI $=0.96, \mathrm{CFI}=0.96$, and RMSEA $=0.07)$ than the one-factor model $\left(\chi^{2}=242.40\right.$, d.f. $=21$; TLI $=0.51$, IFI $=0.63$, $\mathrm{CFI}=0.63$, and RMSEA $=0.20)$. The four-factor model fit well to the data $\left(\chi^{2}=\right.$ 10.31, d.f. $=9$; TLI $=0.99, \mathrm{IFI}=1.00, \mathrm{CFI}=1.00$, and $\mathrm{RMSEA}=0.02) \quad$ while the variance of the extracted common method factor account only $6 \%$ of the total variance, meaning that common method factor would not evidently threat our relationship analyses. The above evidences provided discriminant validity to the three content areas of ex post i-deals with no serious threat from common 
method bias.

Employer and employee obligations. The Psychological Contract Inventory (PCI, Rousseau, 2000), being adapted by Hui, Lee and Rousseau (2004) for use in China, assessed employee beliefs regarding the employer's as well as their own obligations. Although Hui et al. used only employer obligations in their assessment, as in Rousseau, Lee, Dabos, Hui, and Wang (2007), the present study assessed obligations for both employee and employer from the individual worker's perspective. Transactional contract refers to a short-term exchange of benefits and contributions that are highly monetary or economic in focus with specific performance requirements. In contrast, relational contract refers to a long-term contract without specific performance requirements. Relational contract, in essence, involves mutually satisfying relationship with open-ended arrangements that comprise socio-emotional as well as economic terms. Balanced contract has a long-term orientation but specified performance requirements. It blends elements of relational investments with more explicit performance requirements and contingent rewards. We took the highest loading items from Hui et al. (2004) to assess employer obligations. Overall, exploratory factor analyses supported the underlying structure Hui et al. (2004) had identified for employer obligations. Specifically, as shown in Appendix 1, all the items with acceptable loadings for the transactional, relational, and balanced obligations in Hui et al. (2004) and Rousseau et al. (2007) also loaded onto our data set. We also conducted CFAs to examine the overall factor structure of the employer obligations. Results indicated an acceptable factor structure for employer obligations $\left(\chi^{2}=291.20\right.$, d.f. $=87$; TLI $=0.91$, IFI $=0.93$, CFI $=0.93$, and RMSEA = 0.09). Model comparison with alternative models indicated a minimum threat from the common method bias problem. Cronbach's alpha coefficients for the employer obligations scales were 0.81 for transactional, 0.91 for relational, and 0.92 for balanced respectively, indicating acceptable internal consistency.

A Chinese version of the PCI measures for employee obligations was translated from Rousseau's (2000) PCI measure for use here. In an independent sample of 107 part-time MBA students in China, we adopted measurement for these obligations. To produce a more parsimonious set of items for each employee obligation dimensions, we retained only items with factor loading of 0.50 or above. In a following study by Rousseau et al. (2007), the refined Chinese version of PCI was adopted and further refined to achieve parsimony of measurement. In this study, we retained four items for each of obligation dimensions. In Appendix 2, we listed the EFA results of the MBA sample, Rousseau et al. (2007) study, and the current sample. We also ran a three-factor 
CFA model to examine discriminant validity of the employee obligation measurement. Results yielded acceptable fit indices $\left(\chi^{2}=146.87, d . f .=51\right.$; TLI $=$ 0.93 , IFI $=0.95, \mathrm{CFI}=0.95$, and RMSEA $=0.08$ ). In the same process as described above of assessing common method bias, we didn't find significant threat from the problem. The reliability coefficients for transactional, relational, and balanced dimensions are $0.82,0.75$, and 0.90 , respectively.

Control variables included age, gender ("1" = male; " 2 " = female), and organizational tenure (Kidder, 1998; Morrison, 1994).

\section{Results}

Table 1 presents means, standard deviations, reliabilities, and correlations of studied variables. As shown in the table, the reported extent of ex ante i-deals is lower than ex post i-deals $\left(\right.$ Mean $_{\text {ex ante }}=2.26, S . D .=0.99 ;$ Mean $_{\text {ex post }}=2.83$, S.D. $=0.90 ;$ Mean $_{\text {difference }}=-0.57, t$ (for mean difference $)=9.90, p<0.01$ ), suggesting Chinese employees would rather negotiate special job arrangement after having worked in the organization than at the time of hire. The extent of development i-deals is high (62\%), while flexibility i-deals is much lower (14\%). Of the three domains of ex post i-deals, workload reduction is least negotiated (6\%). Comparing to the finding in Hornung, Rousseau, and Glaser's (2008) German sample, that employee negotiates more development than flexibility i-deals, our sample reports the opposite pattern.

Table 2 shows regression results for testing antecedents of i-deals. Of control variables, gender demonstrates significant relations with both ex ante i-deals $(\beta=$ $-0.15, p<0.01$; Model 1$)$ and ex post i-deals $(\beta=-0.20, p<0.01$; Model 2$)$. Since we code male as "1" and female as "2," the negative regression coefficients indicate male more likely to negotiate with employers, asking for special job arrangements before and after organizational entry.

$\mathrm{H} 1$ states that personal individualism relates to both ex ante and ex post i-deals. Regression results support part of the prediction. In our sample, individualism relates only to ex ante ( $\beta=0.22, p<0.01$; Model 1$)$ but not ex post i-deals $(\beta=$ 0.02 , ns; Model 2). Our sample supports $\mathrm{H} 2$ that predicts social skill's effects on both $e x$ ante and ex post i-deals. The regression coefficients of social skill on ex ante and ex post i-deals are $0.14(p<0.05$; Model 1) and $0.16(p<0.01$; Model 2 ), respectively. Regarding H3 predicting perceived insider status' influence on ex post but ex ante i-deals, regression results show full support of it. Specifically, the beta value for the effect of PIS on ex ante i-deals is -0.03 ( $n s$; Model 1); and for the effect of PIS on ex post i-deals is 0.17 ( $p<0.01$; Model 2). 


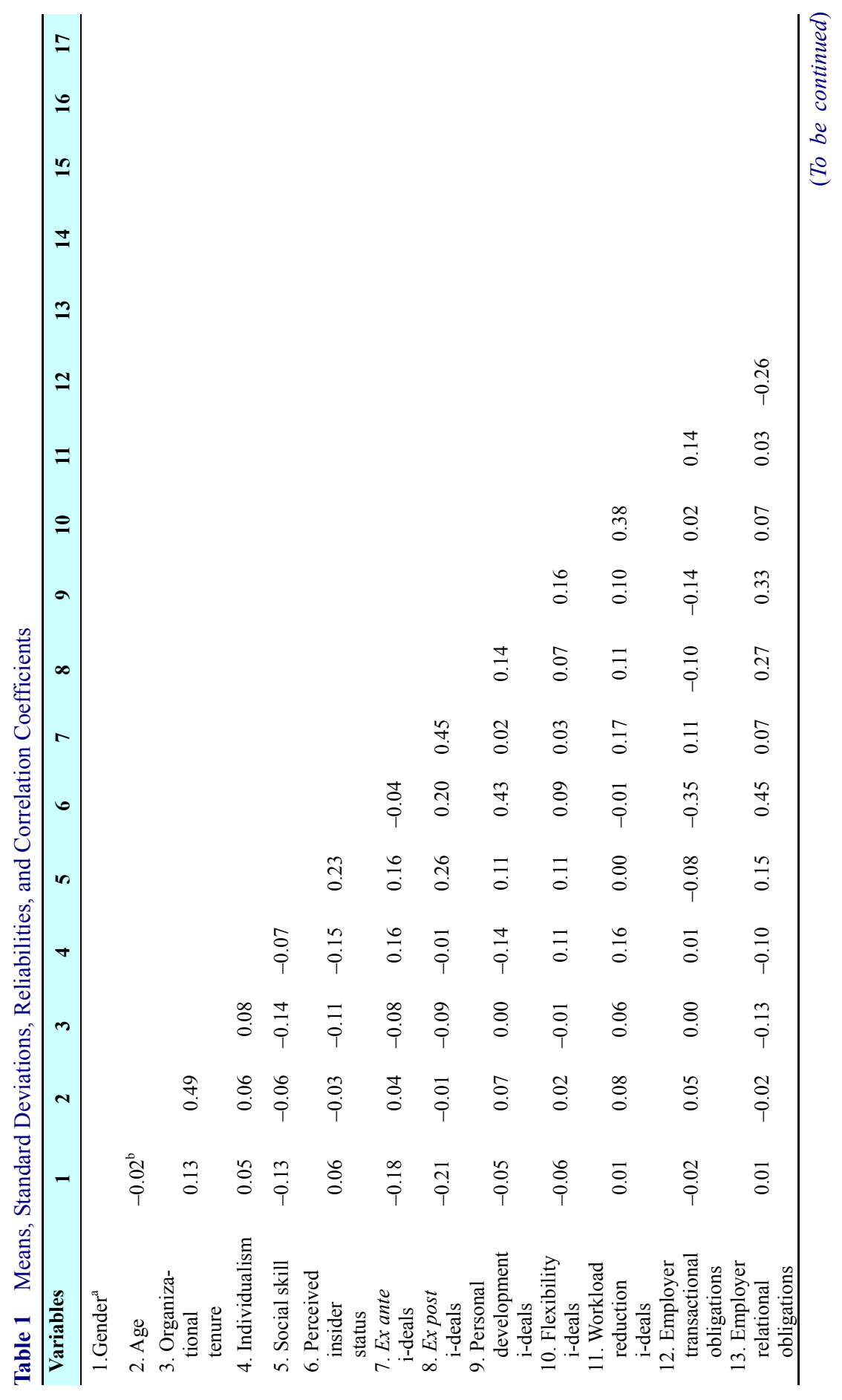




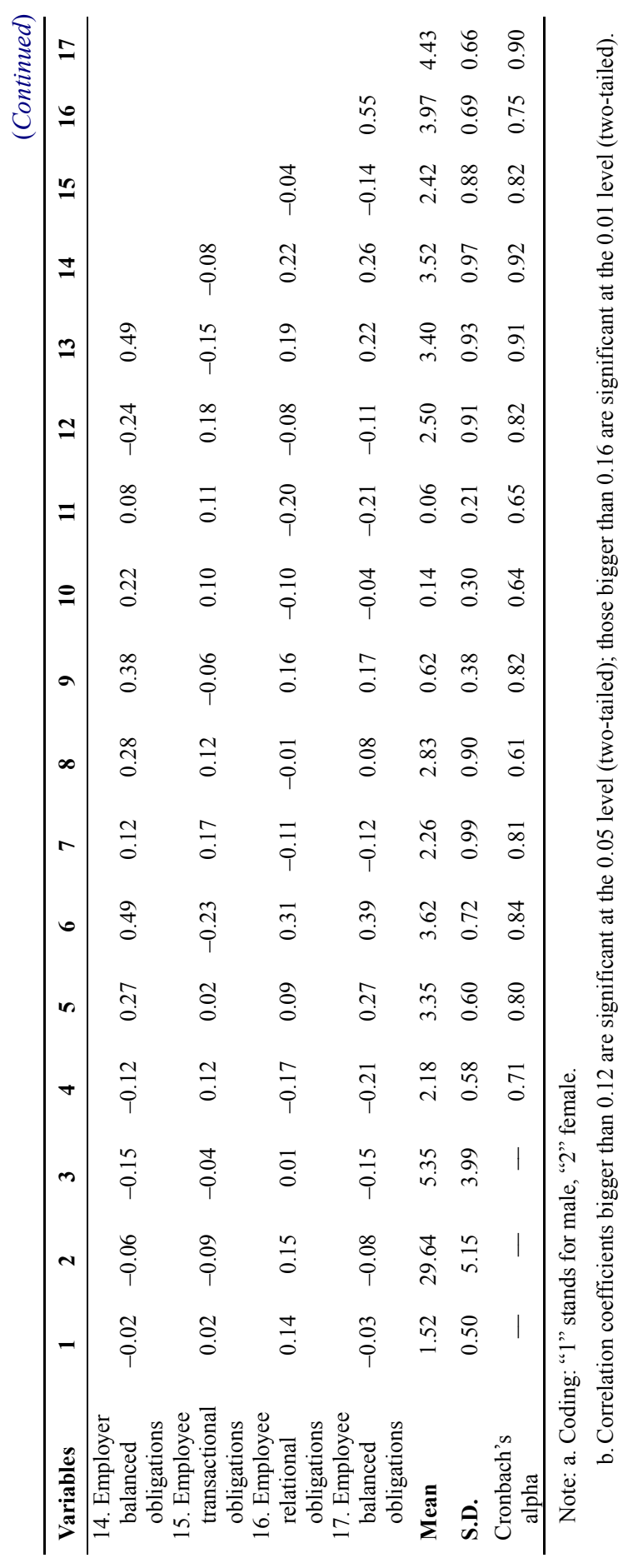


Table 2 Regression Results for Testing Antecedents of i-Deals Timing

\begin{tabular}{lcc}
\hline & \multicolumn{2}{c}{ i-deals timing } \\
\hline Control variables & $\begin{array}{c}\text { Ex ante i-deals } \\
\text { Model 1 }\end{array}$ & $\begin{array}{c}\text { Ex post i-deals } \\
\text { Model 2 }\end{array}$ \\
$\quad$ Gender & $-0.15^{* *}$ & $-0.20^{* *}$ \\
$\quad$ Age & 0.10 & 0.03 \\
$\quad$ Organizational tenure & -0.11 & -0.05 \\
& & \\
$R^{2}$ & $0.04^{* *}$ & $0.06^{* *}$ \\
$F$ & 3.98 & 5.03 \\
& & \\
Predictors & & 0.02 \\
Individualism & $0.22^{* *}$ & $0.16^{* *}$ \\
Social skill & $0.14^{*}$ & $0.17^{* *}$ \\
Perceived insider status & -0.03 & \\
$R^{2}$ & & $0.12^{* *}$ \\
$F$ & $0.10^{* *}$ & 5.82 \\
$\Delta R^{2}$ & 4.77 & $0.06^{* *}$ \\
$\Delta F$ & $0.06^{* *}$ & 6.31 \\
\hline
\end{tabular}

Note: $N=289 ; *$ indicates $p<0.05 ; * *$ indicates $p<0.01$.

Table 3 shows results of testing $\mathrm{H} 4$ to $\mathrm{H} 6$. $\mathrm{H} 4$ postulates ex ante i-deals relate more positively to transactional psychological contract than ex post i-deals. As indicated in the table, employees who have bargained for ex ante i-deals will, on the job, reciprocate transactional obligations to their employers $(\beta=0.16, p<$ 0.05 ; Model 6$)$; on the other side, employers offer corresponding transactional obligations $(\beta=0.14, p<0.05$; Model 3$)$. In addition, results suggest that employees who negotiate ex post i-deals do not necessarily posses high transactional obligations $(\beta=0.08, n s$; Model 6$)$ and the other party, employers reciprocate less transactional obligations $(\beta=-0.17, p<0.05$; Model 3). To make comparison between ex ante and ex post i-deals' effects, we transform those standardized beta coefficients to Fisher's $Z$ values (Fisher, 1915; Hotelling, 1953 ) and examine the significance level of $Z$ value differences. The analyses suggest ex post i-deals' effect on employer transactional obligations is positively superior to that of ex post $\mathrm{i}$-deals $(Z$ value difference $=0.31, t=5.29, p<0.01)$; the effect difference for the employee transactional obligations part is not significant $(Z$ value difference $=0.08, t=1.37, n s)$. Taking above results together, we conclude that $\mathrm{H} 4$, in general, receives support. 
Table 3 Regression Results for Testing Effects of i-Deals on Psychological Contract

\begin{tabular}{|c|c|c|c|c|c|c|}
\hline & \multicolumn{3}{|c|}{ Employer obligations } & \multicolumn{3}{|c|}{ Employee obligations } \\
\hline & $\begin{array}{l}\text { Transactional } \\
\text { Model } 3\end{array}$ & $\begin{array}{l}\text { Relational } \\
\text { Model } 4\end{array}$ & $\begin{array}{l}\text { Balanced } \\
\text { Model } 5\end{array}$ & $\begin{array}{c}\text { Transactional } \\
\text { Model } 6\end{array}$ & $\begin{array}{c}\text { Relational } \\
\text { Model } 7\end{array}$ & $\begin{array}{l}\text { Balanced } \\
\text { Model } 8\end{array}$ \\
\hline \multicolumn{7}{|l|}{ Control variables } \\
\hline Gender & 0.02 & 0.01 & -0.02 & 0.01 & $0.14^{*}$ & -0.04 \\
\hline Age & 0.09 & 0.04 & 0.01 & -0.08 & $0.18^{*}$ & -0.03 \\
\hline $\begin{array}{l}\text { Organizational } \\
\text { tenure }\end{array}$ & -0.04 & $-0.16^{*}$ & $-0.15^{*}$ & -0.01 & -0.08 & -0.12 \\
\hline$R^{2}$ & 0.01 & 0.02 & 0.02 & 0.01 & $0.04 *$ & 0.02 \\
\hline$F$ & 0.58 & 1.71 & 2.06 & 0.56 & 3.49 & 1.85 \\
\hline \multicolumn{7}{|l|}{ i-deals timing } \\
\hline Ex ante i-deals & $0.14^{*}$ & -0.09 & -0.01 & $0.16^{*}$ & -0.09 & $-0.15^{*}$ \\
\hline Ex post $\mathrm{i}$-deals & $-0.17 *$ & $0.26^{* *}$ & $0.24 * *$ & 0.08 & 0.07 & $0.14^{*}$ \\
\hline \multicolumn{7}{|l|}{ i-deals content } \\
\hline $\begin{array}{l}\text { Personal } \\
\text { development }\end{array}$ & $-0.14 *$ & $0.29 * *$ & $0.34 * *$ & -0.07 & $0.19 * *$ & $0.17 * *$ \\
\hline Flexibility & -0.02 & 0.04 & $0.16^{* *}$ & 0.08 & -0.06 & -0.01 \\
\hline $\begin{array}{l}\text { Workload } \\
\text { reduction }\end{array}$ & $0.18 * *$ & 0.00 & -0.05 & 0.06 & $-0.23 * *$ & $-0.22 * *$ \\
\hline$R^{2}$ & $0.09^{* *}$ & $0.18^{* *}$ & $0.25^{* *}$ & $0.07^{*}$ & $0.14 * *$ & $0.13^{* *}$ \\
\hline$F$ & 2.97 & 7.13 & 10.63 & 2.24 & 5.29 & 4.70 \\
\hline$\Delta R^{2}$ & $0.08^{* *}$ & $0.16^{* *}$ & $0.23^{* *}$ & $0.06^{* *}$ & $0.10^{* *}$ & $0.11 * *$ \\
\hline$\Delta F$ & 4.39 & 10.20 & 15.42 & 3.24 & 6.16 & 6.30 \\
\hline
\end{tabular}

Note: $N=289$; * indicates $p<0.05 ; * *$ indicates $p<0.01$.

$\mathrm{H} 5$ predicts ex post i-deals relate more positively to relational and balanced psychological contracts than ex ante i-deals. As shown in Table 3, ex post i-deals' effects on employer relational and balanced obligations are positively significant ( 0.26 and 0.24, $p<0.01$; Model 4 and 5) while ex ante i-deals' effect on the two types of obligations are not significant $(-0.09$ and $-0.01, n s$; Model 4 and 5$)$. We conduct the same Fisher's $Z$ transformation and comparison analyses as described to test $\mathrm{H} 4$. Results suggest that the effect of ex post i-deals on employer relational obligations is positively superior to that of ex ante i-deals $(Z$ value difference $=0.35, t=6.03, p<0.01$ ); similarly, the effect difference for the balanced obligations part is significant $(Z$ value difference $=0.25, t=4.31, p<$ 0.01). Above results suggest that $\mathrm{H} 5$ gets support from the employer obligations side. Identical comparison analyses suggest ex post i-deals' effect on 
employee balanced obligations is positively superior to that of ex ante i-deals $(Z$ value difference $=0.29, t=4.94, p<0.01)$. Ex post and ex ante i-deals' effects on employee relational obligations show significant difference $(Z$ value difference $=$ $0.16, t=2.70, p<0.01$ ), though both effects, individually, are "not-so-significant" $\left(\beta_{\text {ex post }}=0.09, \beta_{\text {ex ante }}=-0.06, n s\right)$. In sum, $\mathrm{H} 5$ receives well support from both employer- and employee-obligation aspects.

H6 predicts that personal development i-deals relate more positively to relational and balanced contracts while flexibility and workload reduction i-deals relate more positively to transactional contracts. Results of comparison analyses suggest: (1) personal development, as predicted, relates more positively to relational and balanced than to transactional obligations, and the difference of effects is manifest for both employer- and employee-obligation perspectives; (2) workload reduction i-deals, as predicted, manifest more positively relationship with transactional obligations than with relational and balanced contracts, in both employer- and employee-obligation aspects; (3) flexibility i-deals could, in neither employer- nor employee-obligation aspects, manifest more positively relationship with transactional obligations than with relational and balanced contracts. In sum, H6 receives only partial support.

Fig. 1 is plotted to visually demonstrate our findings regarding the relationships among the studied key variables, individualism, social skill, perceived insider status, i-deals timing and content, and employer and employee psychological contracts.
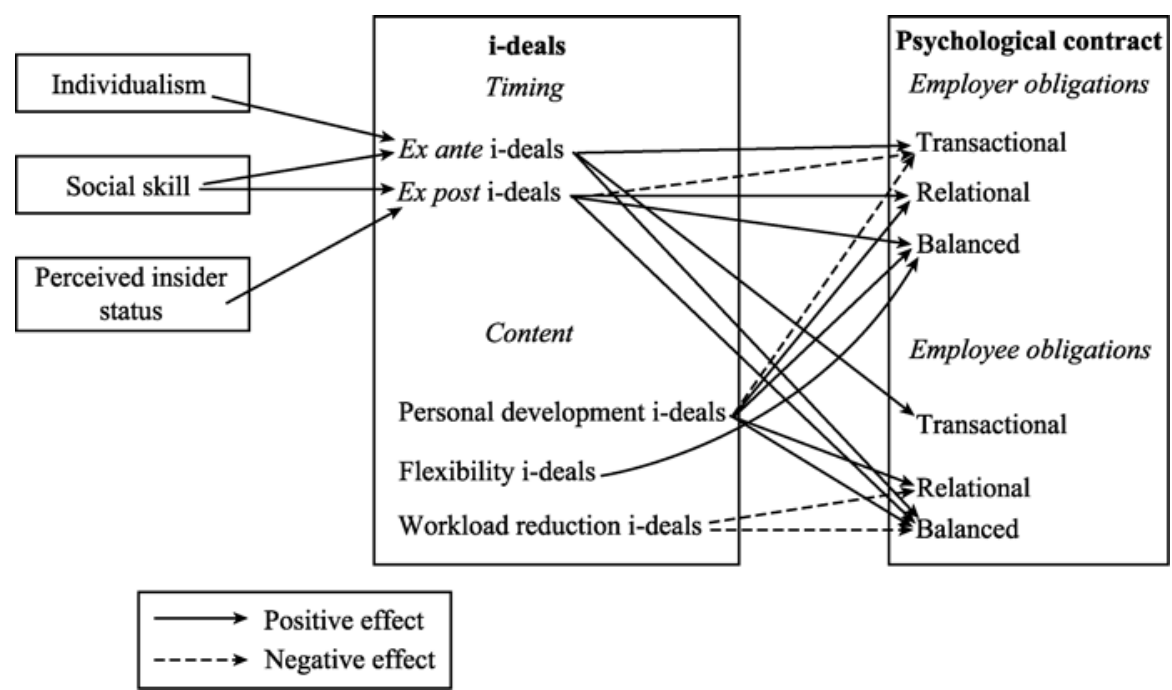

Fig. 1 Structural Model for Result Summary 


\section{Discussion}

\subsection{Theoretical Contributions}

The overall purpose of the study is to examine antecedents and consequences of i-deals, the emerging HR practices in the new knowledge era. Doing so, we draw a rather comprehensive picture of employment relationship (ER). Idiosyncratic deals refer to those features of employment conditions and terms as well (Rousseau, 2001a). On the other hand, psychological contracts reflect an individual's subjective experience of the employment relationship. Scholars (i.e., Hornung et al., 2008; Rousseau, 2001a) have called the empirical examination of the objective-subjective relations of ER. Our study does not only offer understanding of the objective-subjective connections in a non-western cultural context but also, tries to examine antecedents and consequences of them in a resource-exchange frame, which provides a unique angle beyond Hornung et al. (2008) to understanding the novel employment relationship in the Chinese context.

Comprehensiveness is one of virtues of the study since we incorporate in the model: (1) both timing and content of i-deals; (2) both employer- and employee-perspectives plus all the three domains of psychological contract. Though relationships among the major variables are rather complicated, adopting the resource exchange frame helps map out the major findings of the study. First, compared to ex post i-deals, ex ante i-deals are in nature more "economic" than "social-relational orientated" (Rousseau, Ho, and Greenberg, 2006). In the study, we find Chinese employees tend to negotiate more ex post than ex ante i-deals. This is consistent with Rousseau, Ho, and Greenberg's (2006) prediction of Western counterpart. Personal value of individualism relates to ex ante but not ex post i-deals. This at least suggests individualist Chinese are more economic oriented than normal (Chen, 1995). Perceived insider status, reflecting the employee's social resources and also on-the-job working experience, on the other hand relates only to ex post i-deals that emphasize quite a lot on social interaction and exchange with the employer. These results, though not straightforward, inherently reecho Rousseau's (2001b) arguments, which state that both personal values/believes and former socializing experiences influence employees' initial contracting while once on the job, working experiences become the dominant factors affecting employment relationship.

Second and regarding the relationship between i-deals timing and psychological contracts, we find that compared to ex post ones, ex ante i-deals related more positively to transactional contracts and more negatively to relational and balanced contracts. Third and regarding the relationship between i-deals content and psychological contracts, we find that development i-deals 
relate ideally to relational and balanced contracts. These results support the theorizing (e.g., Rousseau, 1995; 2001a; Rousseau, Ho, and Greenberg, 2006) of ex ante, ex post, and development i-deals' nature on the economic versus social-relational dichotomy. The current study, could not offer clear conclusions regarding the nature of flexibility and workload reduction i-deals, since their effects on contracting are not-so consistent and obvious as well.

\subsection{Practical Implications}

Our study offers several practical implications. From the employee perspective, an employee who wants to bargain for individualized employing arrangements should first facilitate his/her own social skill. He/she should have the notion of exchange equity in mind. For a successful negotiation, he/she has to know that the special arrangements correspondingly mean "special contributions" to the organization. Asking for development i-deals will benefit both the employer and him/herself.

From the organization and employer perspective, organizations should recruit less individualistic candidates in order to avoid frequent negotiating with such employees for unstandardized employment conditions. It is expected that the management of an organization establish regulations as well as formal procedures to identify value talents who need to be granted i-deals. However, not all timing and contents of i-deals are proper for offering. I-deals negotiated before organizational entry will strengthen both employee and employer transactional obligations, thus improving human resource costs and blocking on-job motivations. If required by employees for i-deals, organizations should encourage on-the-job negotiation after having known the potential as well as psychological contracts embedded by the employees. Organizations had better, via granting talents personal development than other types of i-deals, enhance the talents' career success and keep high level of retention of them.

\subsection{Limitations and Directions for Future Studies}

Several limitations are worth discussing. First, although we collected two waves of data at different time, we can not eliminate all concerns of the common method bias problem (Podsakoff et al., 2003), specially when dealing with causal relationship tests. Indeed, we administrate antecedent variables (especially, perceived insider status) and i-deals timing in the same wave and information-source as well. However, we have tried our best to relieve the threat via constituting different rating format and creating possible psychological separation between the two sets of variables. Clearly, further researches should employ more rigorous design to rule out the potential common method bias. 
Second, as discussed previously, our model appears rather comprehensive since it involves quite a few sets of constructs. In addition, some constructs are operationalized to different forms and aspects (i.e., the construct psychological contract has six specific variables). To avoid too-high-complexity, we ignore all examinations of interactions among variables or moderating effects. We see some interactions are rather relevant and important to our frame. For example, scholars and practitioners might be interested in the moderating effect of individualism and perceived insider status on the social skill-negotiation of ex ante and ex post i-deals. Further, examining the interactions between employer and employee psychological contracts on outcome variables could also offer important implications. These call for more "tiny but precise" design and investigations.

Third, when considering psychological contracts, we assume the equality of employer and employee obligations on a particular form - transactional, relational, or balanced. Indeed, equality of obligations has to be based upon the equal reciprocity from two parties with equal status. In the reality, they do not necessarily share absolute equivalence. Especially and evidently, in the Chinese contexts, employees and organizations possess unequal status. This unequivalence will demolish part of underpinnings of our arguments. Future studies should pay close attention to this issue when examining employment relationships in China.

Acknowledgements The work is supported by the Research Grants Council of the Hong Kong Special Administrative Region, China (No. HKU444208). The work described in this paper is also supported by the Walsh Professorship of the College of Business Administration, Northeastern University.

\section{References}

Argyris, C. 1960. Understanding organizational behavior. Homewood, IL: Dorsey Press.

Blau, P. 1964. Exchange and power in social life. New York: Wiley.

Brislin, R. W. 1980. Translation and content analysis of oral and written material. Handbook of Cross-cultural Psychology, 2: 339-444.

Chen, C. C. 1995. New trends in rewards allocation preferences: A Sino-U.S. comparison. Academy of Management Journal, 38: 408-428.

Earley, P. C. 1993. East meets West meets Mideast: Further explorations of collectivistic and individualistic work groups. Academy of Management Journal, 36: 319-348.

Earley, P. C., \& Gibson, C. B. 1998. Taking stock in our progress on individualism-collectivism: 100 years of solidarity and community. Journal of Management, 24: $265-304$.

Ferris, G. F., Witt, L. A., \& Hochwarter, W. A. 2001. Interaction of social skill and general mental ability on job performance and salary. Journal of Applied Psychology, 86: 1075-1082.

Fisher, R. A. 1915. Frequency distribution of the values of the correlation coefficient in samples of an indefinitely large population. Biometrika, 10: 507-521. 
Foa, U. G., \& Foa, E. B. 1974. Societal structures of the mind. Springfield, IL: Thomas.

Foa, U. G., \& Foa, E. B. 1976. Resource theory of social exchanges. In J. S. Thiabut, J. Spence, R. Carson (Eds.), Contemporary topics in social psychology: 99-131. Morristown, NJ: General Learning Press.

Foa, U. G., \& Foa, E. B. 1980. Resource theory: Interpersonal behavior as exchange. In K. J. Gergen, M. S. Greenberg, R. H. Willis (Eds.), Social exchange: Advances in theory and research: 77-94. New York: Plenum Press.

Hochwarter, W. A., Witt, L. A., Treadway, D. C., \& Ferris, G. R. 2006. The interaction of social skill and organizational support on job performance. Journal of Applied Psychology, 91: $482-489$.

Hofstede, G. 1980. Culture's consequences. Beverly Hills, CA: Sage.

Hornung, S., Rousseau, D. M., \& Glaser, J. 2008. Creating flexible work arrangements through idiosyncratic deals. Journal of Applied Psychology, 93: 655-664.

Hotelling, H. 1953. New light on the correlation coefficient and its transforms. Journal of the Royal Statistical Society, 15: 193-225.

Hui, C., Lee, C., \& Rousseau, D. M. 2004. Psychological contracts in China: Investigating instrumentality and generalizability. Journal of Applied Psychology, 89: 311-322.

Nunnally, J. C. 1978. Psychometric theory (2nd edition). New York: McGraw-Hill.

Peterson, R. S., Ranganathan, R., Chi, S. C. S., Tsai, H. H., \& Chen, S. C. 2006. The key role of personal values in decoupling task conflict from relationship conflict. Paper presented at the Academy of Management Annual Conference, Atlanta, GA, August, 2006.

Podsakoff, P. M., MacKenzie, S. B., Lee, J. Y., \& Podsakoff, N. P. 2003. Common method bias in behavioral research: A critical review of the literature and recommended remedies. Journal of Applied Psychology, 88: 879-903.

Rohan, M. J. 2000. A rose by any name? The values construct. Personality and Social Psychology Review, 4: 255-277.

Rokeach, M. 1973. The nature of human values. New York: Free Press.

Rousseau, D. M. 1995. Psychological contracts in organizations: Understanding written and unwritten agreements. Thousand Oaks, CA: Sage Publications.

Rousseau, D. M. 1996. Changing the deal while keeping the people. Academy of Management Executive, 10: 50-61.

Rousseau, D. M. 2000. Psychological contract inventory: Technical report. Pittsburgh: Carnegie Mellon University.

Rousseau, D. M. 2001a. The idiosyncratic deal: Flexibility versus fairness? Organizational Dynamics, 29: 260-273.

Rousseau, D. M. 2001b. Schema, promise and mutuality: The building blocks of the psychological contract. Journal of Occupational and Organizational Psychology, 74: 511-542.

Rousseau, D. M. 2005. I-deals: Idiosyncratic deals employees bargain for themselves. New York: M. E. Sharpe.

Rousseau, D. M., \& Fried, Y. 2000. Location, location, location: Contextualizing organizational behavior. Journal of Organizational Behavior, 22: 1-15.

Rousseau, D. M., Ho, V. T., \& Greenberg, J. 2006. I-deals: Idiosyncratic terms in employment relationships. Academy of Management Review, 31: 977-994.

Rousseau, D. M., Hornung, S., \& Kim, T. G. 2008. Idiosyncratic deals: Testing propositions on timing, content, and the employment relationship. Working paper, Carnegie Mellon University, Pittsburgh, PA

Rousseau, D. M., \& Kim, T. G. 2006. Idiosyncratic deals and the employment relationship. Paper presented at the British Academy of Management, Belfast, Northern Ireland, 
September, 2006

Rousseau, D. M., Lee, C., Dabos, G., Hui, C., \& Wang, H. 2007. Firm culture as an antecedent of the employee psychological contract: Its alignment and fulfillment. Paper presented the Academy of Management Annual Conference, Philadelphia, PA, August, 2007

Schwartz, S. H. 1992. Universals in the content and structure of values: Theory and empirical tests in 20 countries. Advances in Experimental Social Psychology, 25: 1-65

Stamper, C. L., \& Masterson, S. S. 2002. Insider or outsider? How employee perceptions of insider status affect their work behavior. Journal of Organizational Behavior, 23: 875-894.

Waterman, A. S. 1984. The psychology of individualism. New York: Praeger.

Wernerfelt, B. 1984. A resource-based view of the firm. Strategic Management Journal, 5: 171-180.

Witt, L. A., \& Ferris, G. R. 2003. Social skill as moderator of the conscientiousness-performance relationship: Convergent results across four studies. Journal of Applied Psychology, 88: 809-820.

Appendix 1 Factor Structure and Loadings: Employer Obligations

\begin{tabular}{|c|c|c|c|}
\hline Scales and items & $\begin{array}{l}\text { Hui et al. } \\
\text { (2004) } \\
\text { loadings }\end{array}$ & $\begin{array}{l}\text { Rousseau } \\
\text { et al. } \\
\text { (2007) } \\
\text { loadings }\end{array}$ & $\begin{array}{l}\text { Current } \\
\text { data } \\
\text { loadings }\end{array}$ \\
\hline \multicolumn{4}{|l|}{ Transactional (alpha $=0.81)$} \\
\hline Short-term employment & 0.71 & 0.69 & 0.71 \\
\hline Makes no commitment to retain me in the future & 0.56 & 0.56 & 0.72 \\
\hline Employment for a specific or limited time & 0.52 & 0.64 & 0.69 \\
\hline Require me to do only limited duties I was hired to perform & 0.51 & 0.58 & 0.60 \\
\hline A job limited to specific well-defined responsibilities & 0.49 & 0.46 & 0.40 \\
\hline It has made no promises to continue my employment & 0.49 & 0.72 & 0.64 \\
\hline \multicolumn{4}{|l|}{ Relational (alpha $=0.91)$} \\
\hline Steady employment & 0.70 & 0.62 & 0.63 \\
\hline Stable benefits to employees' families & 0.65 & 0.67 & 0.85 \\
\hline Concern for my personal welfare & 0.61 & 0.46 & 0.87 \\
\hline Wages and benefits I can count on & 0.55 & 0.66 & 0.87 \\
\hline Concern for my long-term well-being & 0.48 & 0.74 & 0.85 \\
\hline \multicolumn{4}{|l|}{ Balanced $($ alpha $=0.92)$} \\
\hline Skill development that increases my value to the firm & 0.78 & 0.70 & 0.81 \\
\hline Opportunities for promotion & 0.78 & 0.64 & 0.84 \\
\hline Set ever more difficult and challenging performance goal for me & 0.70 & 0.47 & 0.90 \\
\hline Help me develop externally marketable skills & 0.70 & 0.75 & 0.88 \\
\hline
\end{tabular}


Appendix 2 Factor Structure and Loadings: Employee Obligations

\begin{tabular}{|c|c|c|c|}
\hline Scales and items & $\begin{array}{l}\text { MBA } \\
\text { sample } \\
\text { loading } \\
\end{array}$ & $\begin{array}{l}\text { Rousseau } \\
\text { et al. } \\
(2007) \\
\text { loadings }\end{array}$ & $\begin{array}{l}\text { Current } \\
\text { data } \\
\text { loadings }\end{array}$ \\
\hline \multicolumn{4}{|l|}{ Transactional $($ alpha $=0.82)$} \\
\hline Perform only specific duties for which I am compensated & 0.64 & 0.61 & 0.74 \\
\hline I have no future obligations to this employer & 0.64 & 0.65 & 0.78 \\
\hline Work here for a limited time only & 0.60 & 0.60 & 0.77 \\
\hline Do only what I am paid to do & 0.60 & 0.61 & 0.70 \\
\hline \multicolumn{4}{|l|}{ Relational (alpha $=0.75)$} \\
\hline Make personal sacrifices for this organization & 0.72 & 0.49 & 0.80 \\
\hline Commit myself personally to this organization & 0.64 & 0.69 & 0.71 \\
\hline Be a steady employee & 0.63 & 0.73 & 0.61 \\
\hline Do what it takes to keep my job & 0.51 & 0.50 & 0.53 \\
\hline \multicolumn{4}{|l|}{ Balanced (alpha $=0.90)$} \\
\hline Build skills to increase my value to this organization & 0.71 & 0.83 & 0.78 \\
\hline Continuously exceed my formal accountabilities & 0.76 & 0.73 & 0.82 \\
\hline Seek out assignments that enhance my employability & 0.73 & 0.62 & 0.79 \\
\hline Make myself increasingly valuable to my employer & 0.65 & 0.77 & 0.79 \\
\hline
\end{tabular}

